\title{
Parent Artery Occlusion: A Well-Established Technique
}

lons n their recent publication "Parent Artery Occlusion in Large, Giant, or Fusiform Aneurysms of the Carotid Siphon: Clinical and Imaging Results," Labeyrie et $\mathrm{al}^{1}$ retrospectively reviewed 56 patients treated with aneurysm trapping by using detachable platinum coils. The authors make 2 controversial statements, neither of which is referenced, and with which we take issue:

1) "Proximal occlusion without trapping (surgical or endovascular) has a lower rate of aneurysmal retraction and should not be performed for carotid aneurysms."

2) "Endovascular parent artery occlusion with trapping of the aneurysm has long been considered the reference treatment for large, giant, or fusiform aneurysms of the carotid siphon." [Italics added for emphasis.]

Several large series of giant aneurysms treated with parent artery occlusion have, in fact, demonstrated the safety and efficacy of this treatment alone. Even in the setting of initial retrograde filling, these aneurysms often progress to complete thrombosis. In 1994, Drake et $\mathrm{al}^{2}$ published a series of 160 anterior circulation giant aneurysms treated with Hunterian proximal occlusion. Eighty of 82 petrous and cavernous aneurysms were obliterated with proximal occlusion, only 4 of which required trapping. In 1987, Fox et $\mathrm{al}^{3}$ reported 58 patients with anterior circulation giant aneurysms, with all 37 aneurysms below the ophthalmic

http://dx.doi.org/10.3174/ajnr.A4353 segment and 10 of 21 supraclinoid aneurysms obliterated with proximal occlusion alone without the need for trapping. We have been unable to find evidence in the literature demonstrating the inferiority of proximal occlusion as a first-line procedure. Furthermore, the addition of distal occlusion may have contributed to the authors' increased rate of ischemic events in $27 \%$ of patients, because the origins of perforating vessels will, by definition, be occluded across any trapped segment. We would argue that proximal occlusion of the parent artery without trapping remains a viable time-honored treatment option for giant saccular and fusiform carotid aneurysms.

\section{REFERENCES}

1. Labeyrie MA, Lenck S, Bresson D, et al. Parent artery occlusion in large, giant, or fusiform aneurysms of the carotid siphon: clinical and imaging results. AJNR Am J Neuroradiol 2015;36:140-45

2. Drake CG, Peerless SJ, Ferguson GG. Hunterian proximal arterial occlusion for giant aneurysms of the carotid circulation. J Neurosurg 1994;81:656-65

3. Fox AJ, Vinuela F, Pelz DM, et al. Use of detachable balloons for proximal artery occlusion in the treatment of unclippable cerebral aneurysms. J Neurosurg 1987;66:40-46

C.M. Benson D.M. Pelz

S.P. Lownie Departments of Medical Imaging and Clinical Neurological Sciences University Hospital London, Ontario, Canada 